\title{
Modelling the Integration of BP and IT Using Business Process Simulation
}

\author{
Alan Serrano* and Mariëlle den Hengst** \\ *Corresponding Author \\ Department of Information Systems and Computing \\ Brunel University \\ Uxbridge UB8 3PH, Middlesex, United Kingdom \\ Telephone +44 (0) 1895274000 ext 3622 fax: +44 (0) 1895251686 \\ e-mail: Alan.Edwin.Serrano-Rico@brunel.ac.uk \\ **Delft University of Technology \\ Faculty of Technology, Policy and Management \\ P.O. Box 5015, 2600 GA Delft, The Netherlands \\ Telephone: +31-15-2788542 fax: +31-15-2783429 \\ e-mail: m.den.hengst@tpm.tudelft.nl
}




\section{Modelling the Integration of BP and IT Using Business Process Simulation}

\section{Abstract}

Information Technology (IT) and Business Process (BP) communities argues that the use of IT to support business processes can bring a number of benefits to the organisation. Most of these benefits, however, can only be seen after the implementation of such technology. Moreover, there are many cases where the benefits brought by the implementation of IT do not fulfil the organisation's expectations. One reason of this may happen is because research in BP and IS domains show little indication of which modelling methods, techniques or tools can help organisations to foresee the benefits of the integration of IT with BP. This paper describes the insights gained during a UK funded research project, namely ASSESS-IT, which used simulation techniques to address this problem. Considering IT as a two layered system, namely Information Systems (IS) and Computer Networks (CN), ASSESS-IT aimed to depict the benefits that new IT may bring to the BP. This paper uses the outcomes derived from ASSESS-IT to suggest that, in some cases; the relationship between BP and IT could be better understood by looking at the relationship between BP and IS alone. It then proposes an alternative simulation framework, namely ISBPS, that provides the means to develop simulation models that portray quantifiable metrics of the integration of BP and IS, offering in this way an alternative mechanism that can help BP and IS analyst to foresee the benefits that the insertion of a given IS design may bring to the organisational processes.

Keywords: IS design, BP design, Simulation, Integration

\section{Introduction}

The integration of business process (BP) and information technology (IT) has long been one of the major concerns for both business process and information technology practitioners. For instance, many business process innovation approaches strongly argue that information technology (IT) must be seen as one of the major enablers of organisational change rather 
than a tool to implement business processes (Davenport, 1993, Hammer and Champy, 1993). It is argued that the success of IT to enable process redesign lies in Information Systems (IS) strategy integration (Grover et al., 1994). This view is also shared by the information systems community. For instance, most of the information systems methodologies suggest that a key factor towards a successful information system implementation is strongly related to the adequate integration of the proposed information system with the business process that it aims to support. Therefore, most of IS methodologies includes one or more phases within the system's development cycle to ensure this is the case.

Despite the fact that there is enough evidence that suggests that the success of IT to enable process performance is strongly related to the strategies to integrate BP and IT, there is little research that specifies which modelling techniques are more suitable to model BP and IT integration. The design of either business process or information systems has long been supported by the use of different modelling techniques and a large number of BP and IT modelling techniques has been proposed. Most of these techniques, though, are designed to model different aspects of the BP or IS design process but not to address the integration of both domains. This paper argues that one of the challenges posed by the BP and IT integration paradigm is related to the identification and use of adequate techniques or tools to model this relationship. To this end, this paper suggests that business process simulation (BPS) can be used to model the integration of BP and IS. To do so, however, the BPS model needs some modifications. Consequently, this paper presents a modelling framework, namely ISBPS that describes the steps needed to build business process simulation models that take into account their integration with the supporting IS.

The rest of this paper is structured as follows. Section 2 provides evidence to support the claims of this paper together with some evidence that posits simulation as one of the most suitable candidates to address the BP and IT integration problem. Section 3 describes the 
research strategy followed in this paper. Because the ISBPS framework is based on previous research performed by the authors of this paper, specifically on a simulation framework that aimed to address the same problem, namely ASSESS-IT, Section 4 describes the rationale of the ASSESS-IT framework together with the findings that drives to the proposal of the ISBPS framework. Section 5 describes case study used to test both the ASSESS-IT and the ISBPS frameworks. The case study used was not thought to be exhaustive but rather to illustrate that the development of simulation models to capture the behaviour of business process and information systems is possible, and that the results from such models provide relevant information that can be used to model the integration of BP and IT. Section 6 analyses the results derived from the ASSESS-IT framework, which in turn, are the foundations to propose the ISBPS framework. Section 7 describes the key steps of the ISBPS framework that addresses BP and IS integration whereas Section 8 describes the application of the framework in the case study proposed in section 5. Section 9 is a discussion of the findings derived from the ISBPS framework and how these are related to the theory discussed in section 2. Finally section 10 discusses the advantages and limitations of this research.

\section{Simulation to Model Business Process and Information System Integration}

Process Innovation is one of the most popular concepts in business management. The study of business processes, however, is not isolated and has always been related to Information Technology (IT). IT is considered one of the most important enablers of process change. For example, in one of the first articles about process innovation, Davenport and Short (1990) argue that together, processes and information technology can be seen as a new industrial engineering paradigm that may revolutionise the way in which organisations operate. This idea is supported by most of the advocators of the process innovation movement. Many of them argue that IT should be seen as an enabler of organisational change rather than as a tool to implement business processes (Davenport, 1993). Childe et al. (1994) 
for example, state that the initiative to move towards process redesign in many cases originates from the IT departments. In one of the first empirical studies on IT-enabled process change (Grover et al., 1994) it is claimed that the success of IT to enable process redesign lies in Information Systems (IS) strategy integration. They contend that the success of IT-enabled process change efforts will succeed only if they are directed through a strong integration with strategy.

This integration approach, however, has posed new challenges to IS and BP practitioners. One of these challenges is related to the identification and use of techniques/tools to model the BP/IT integration process. For example, Davenport's process innovation methodology (1993) suggest different ways that IT can be used to improve process performance. Davenport's framework, however, does not supply enough information related to the specific techniques that can be used to model this relationship. Similarly to this work, Kettinger et al. (1997) proposed the Stage-Activity (S-A) framework for BPR. Despite this framework identifies some BP modelling techniques and tools that can be used in the framework, these techniques are mainly focused to address BP aspects and not to address the BP and IT integration process.

The problem related to the identification of techniques that can aid to model integrated BP and IS solutions can also be found in the IS domain. Hedman \& Kelling (2003) for example, claim that IS research tends are unable to measure the added value of IS investments to the business. Agerfalk \& Eriksson (2004) argue that one of the reasons that causes this problem is the limitation of traditional IS development approaches to integrate important properties of the business in the IS models.

One alternative IS paradigm that has looked at the integration of BP and IT is Enterprise Resource Planning (ERP). ERP technology supporters claim that this problem can be addressed by encouraging organisations to shift to the adoption of an integrated IT 
infrastructure that automates their business processes. This approach, however, focuses very little on the BP and IT modelling problem because the proposed solution uses predefined business process, hence there is little need to model current or alternative process. Furthermore, ERP systems are not suitable for all organisations, especially for those where the ERP system needs to co-exits alongside other organisation's information systems (Themistocleous and Irani, 2001, Themistocleous, 2004). Because ERP systems have their own philosophy for business process automation and integration, they leave organisations with little room for experimentation and creativity.

Although the literature does not provide much evidence of which tools can aid to design integrated BP and IT solutions, it offers a large number of modelling techniques and tools that have been used for organisational design. A modelling technique that is very popular amongst BP practitioners is business process simulation (BPS). Existing literature in this domain provides an extensive list of reasons to support this argument. Amongst the most relevant are:

- Simulation modelling supports the creation of dynamic models of organisational processes and information systems (Hlupic and Robinson, 1998, Vreede, 1998). Dynamic models offer more opportunities for evaluating business processes and information systems (Paul et al., 1998).

- The visual interactive features of many simulation packages allow multidisciplinary team members to understand the model and communicate about it (Paul et al., 1998, Vreede and Verbraeck, 1996).

- Simulation modelling tools provide a structural environment in which one can understand, analyse and improve business processes (Pegden et al., 1995). 
- Simulation models describe processes in the organisational system with graphical symbols, as static models do, and provide quantitative information about these processes (Pegden et al., 1995).

- Besides capturing the processes, simulation also supports the quantitative evaluation of different alternatives before implementation (Paul et al., 1998). Quantitative process metrics that can be addressed by simulation include, but are not limited to, costs, cycle time, serviceability, and resource utilisation (Pegden et al., 1995, Sierhuis et al., 2003). These metrics also form the basis for evaluating alternatives in BPR (Giaglis, 1999, Levas et al., 1995).

BP and IT practitioners have tried to use the advantages provided by BPS techniques to address the BP and IT modelling integration problem. Painter et al. (1996), for example, propose a simulation-based methodology, namely BPR-II, to assess the impact of changes to business processes and the IT infrastructure that support those processes. They argue that the BPR-II methodology and an accompanying automated support environment will provide the ability to link models of both business process and the supporting IT infrastructure. Painter et al. propose a three-layered structure that defines the relationship between BP and IT: BP, computer networks (CN), and IS. To this end, it is proposed to use the IDEF3 method as the key mechanism for process capture at all three levels, namely business process, application (IS) and network processing, and to directly generate the structure and logic of simulation models reflecting these levels. This research agrees with Painter et al's approach in the way that highlights the benefits of using business process simulation to modelling the integration of BP and IT. A limitation of the approach suggested by Painter et al, however, is that it requires the development of three different models (BPS, IDEF3 and CNS) as well as the refinement of the simulation models derived from such models. This paper extends the research in this domain by investigating the suitability of using BPS techniques alone. To this 
end, this research proposes an alternative framework that applies business process simulation techniques to depict the interactions between business processes and information systems, namely the ISBPS framework. The ISBPS framework is based on the knowledge gained from a UK funded research project, namely ASSESS-IT, which used simulation techniques to model integration of BP and IT (Giaglis et al., 1999).

\section{Research Methodology}

This paper attempts to investigate the relationship between IT and BP and to provide modelling mechanisms that help practitioners to depict the integration between these two domains. Therefore, a research strategy that reflects the relative objectivity of the technical artefacts, namely IT, and the subjectivity of the social/organisational issues, namely BP, could be one that combines both scientific and interpretivist views (Braa and Vidgen, 1995). One such research strategy that meets these demands is a case study (Irani et al., 1999). A case study research strategy is one that uses systemised way of observing (Weick, 1984). A case study method has the flexibility not to require explicit control or to manipulate variables, to study a phenomena in its natural context, and to use qualitative tools and techniques for data collection and analysis (Yin, 1994). This suggests that this particular method may be appropriate for the research proposed in this paper.

A case study strategy can be differentiated by the objectives it aims to accomplish. The most common are discovery and theory building (Benbasat et al., 1988), theory testing (Lee, 1989), and discovery, building and testing (Irani et al., 1999).

For this research, a single case study approach is employed for discovery, building and testing. The case study is used first to confirm or reject the hypothesis that the ASSESS-IT framework can be used to model BP and IT integration (theory testing). One of the advantages of using a single case study is that concentrating upon the same case study permits a full and rich understanding of the phenomena (discovery). This new knowledge will 
help reflection about the hypothesis proposed and to develop the ISBPS framework (theory building). Because the ISBPS framework aims to address the limitations found in the ASSESS-IT framework the former is tested using the ASSESS-IT case study.

Both the ISBPS and ASSESS-IT frameworks are simulation exercises per se. Therefore the data needed for the research proposed here is very similar to that used for a simulation study. According to Banks et al. (2000) the objectives of the study dictate the kind of data to be collected. Banks et al. argues that determining appropriate distributions for input data provides the driving force for a simulation model. Typical input data are the distributions of time between arrivals and service time. To this end Banks et al. proposes four basic steps in the development of a useful model input data. These are:

- Collect data from the real system of interest.

- Identify a probability distribution to represent the input process

- Choose the parameters that determine a specific instance of the distribution family

- Evaluate the chosen distribution and the associated parameters for goodness-of-fit

These steps are followed to develop the simulation models in both ISBPS and ASSESSIT framework. Similarly, to validate the simulation models, the validation steps proposed by Banks et al are followed. Because the ISBPS framework models also the information system used to support the business process, IS modelling techniques, such as use case and activity diagrams are also used in this study. Figure 1 illustrates the research strategy. 


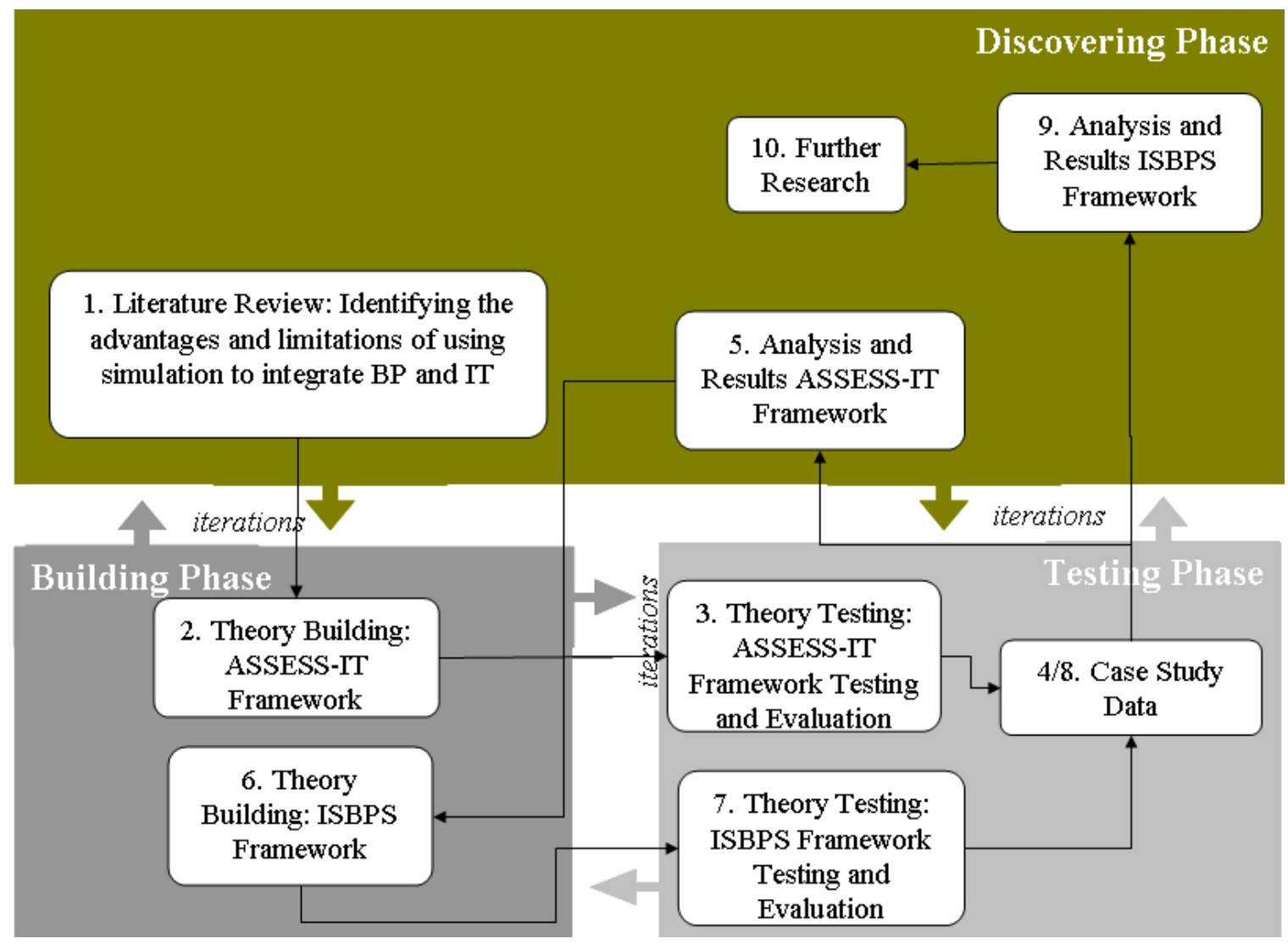

Figure 1 Research Strategy

\section{The ASSESS-IT framework: Discovery Phase}

The fact that simulation has been successfully used in the process domain posits this technique as one suitable candidate to address the business process and information technology integration challenge. The BP domain has largely used Business Process Simulation (BPS) models to assess the impact that changes to business processes may have on the organisation and to explore different BP scenarios (Gladwin and Tumay, 1994, MacArthur et al., 1994, Warren et al., 1995, Hlupic and Robinson, 1998, Giaglis, 1999). A Business Process Simulation exercise, though, does not aim to provide information related to the ways new IT may improve business process performance. The ASSESS-IT project investigated the suitability of combining business process and computer network simulation (CNS) models to provide this information. Considering that existing CNS tools are able to model both the computer network behaviour and the way IS applications may affect network 
behaviour (Law and McComas, 1994). The modelling framework proposed in ASSESS-IT combines the ability of BPS models to portray the organisational aspects and relates this information to a CNS model to address both IS and CN factors that may have an impact on BP process performance. The following paragraph outlines the main objectives pursued by the ASSESS-IT framework.

The ASSESS-IT framework recommends a series of steps to develop simulation models that exchange performance measurements between BP and CN simulation models, reflecting in this way the impact that changes to IT infrastructure (CN and IS) may have on BP performance. The ASSESS-IT framework is based on Banks et al. (2000) simulation steps. The simulation steps proposed in Banks et al. are designed to develop a single simulation model. Because the ASSESS-IT framework aimed to share the results obtained from two simulation models, namely BPS and CNS, so that changes in one model (e.g. CNS) are reflected in the other (e.g BPS), the following modifications were required. For instance, the ASSESS-IT framework duplicates Banks et al's steps for each of the models (BPS and CNS). To coordinate the design of BP and IT so the corresponding models integrate BP and IT models, three moments of interaction are included. The problem formulation and setting of objectives and overall project plan steps are performed together for the BP and CN simulation models. After model conceptualisation it should be verified that IT issues are considered in BP design and vice versa. And during experimentation, the results of the CNS model are to be integrated with the BP model. A complete description of the ASSESS-IT framework can be found in (Serrano, 2002).

\section{The Case Study}

The case study used to test the ASSESS-IT framework consists of two collaborating organisations in Greece. One company is a branch of a major multinational pharmaceuticals 
organisation (we will refer to this company as Org-A), while the other is a small-sized regional distributor of Org-A’s products (we will refer to this company as 'Org-B').

The case study was carried out within a single business unit, which deals with hospital consumables. The business unit imports products from other Org-A production sites across Europe. The goods are stored in a warehouse that operates as a central dispatch point for all products, which are then distributed to the company's customers via a network of collaborating distributors. One of these distributors is Org-B.

Org-B is a small company that has signed an agreement to act as Org-A's exclusive distributor of Medical unit products. The agreement states that Org-B's responsibilities include:

1. Receiving orders from Org-A customers.

2. Maintaining an adequate inventory of products that fulfil the orders.

3. Distributing the ordered products to customer premises.

Due to the nature of the products, Org-B, as the company in charge of delivering products, has to operate within rigorous deadlines. The agreement between the companies stipulates that each order has to be fulfilled within 24 hours for products delivered within the city of Thessaloniki, or within 48 hours for the rest of northern Greece.

Org-A management has noted, however, that these targets are rarely met in practice. A brief analysis by the companies seemed to attribute the problems to some inefficiencies within the ordering system as well as difficulties being experienced by Org-B in maintaining their inventory at an optimal level. In addition to this the communication system between the two companies was also seen as slow and cumbersome. The effects that these inefficiencies caused were seen as a major source of customer dissatisfaction, so an in-depth analysis of the problem was commissioned. The main objectives of the case study were: 
1. To examine the existing business processes that were felt to be responsible for long lead times for order fulfilment.

2. To determine the sources of problems and propose alternative solutions.

3. To evaluate the potential of introducing appropriate IT to improve communication between the two companies.

In order to calculate the business effects of introducing an IT infrastructure, the ASSESSIT framework aimed to develop a computer network model, including IS design, identify the information that may be relevant to the BPS model and incorporate it in the latter.

\section{ASSESS-IT Framework Analysis of the Results: Discovery Phase}

The CNS model and the BPS model were used to run a number of experiments. Figure 2 shows the results of the BPS model for five different scenarios. The vertical axis represents the time in hours taken to deliver orders to Thessaloniki and Northern Greece, the time taken to deliver backorders to the same destinations, and finally the total time to deliver a complete order to the same locations. The horizontal axis represents the different scenarios that were simulated. The first scenario are the results of the processes as they stand (as-is), followed by a scenario that includes faxing the order list, and then faxing the list twice a week instead of once a week. The last two scenarios include the use of ICTs: using a database to share the information, and using the same database adding one more employee to help in the warehouse. Those scenarios were selected after various experiments with the as-is model and analysing possible BP and IS solutions. For example, it was identified that the warehouse employee was utilised almost $96 \%$ of his time, hence the suggestion of using one extra resource in that process.

The BPS model helped to identify possible process limitations and areas of improvement, including possible IS/IT solutions. It can be seen that one of the scenarios considers the reduction of processing time using a database system. Although the results show that 
backordering lead time was reduced, the total time (orders + backorders) increased. The results suggested that using IT to improve business response time does not necessarily improve process performance. Similar results were found in the computer network modelling phase: the experiments suggested that changes to the network infrastructure and to other parameters (network traffic) did not have a considerable effect on IS performance, and consequently did not affect BP performance.

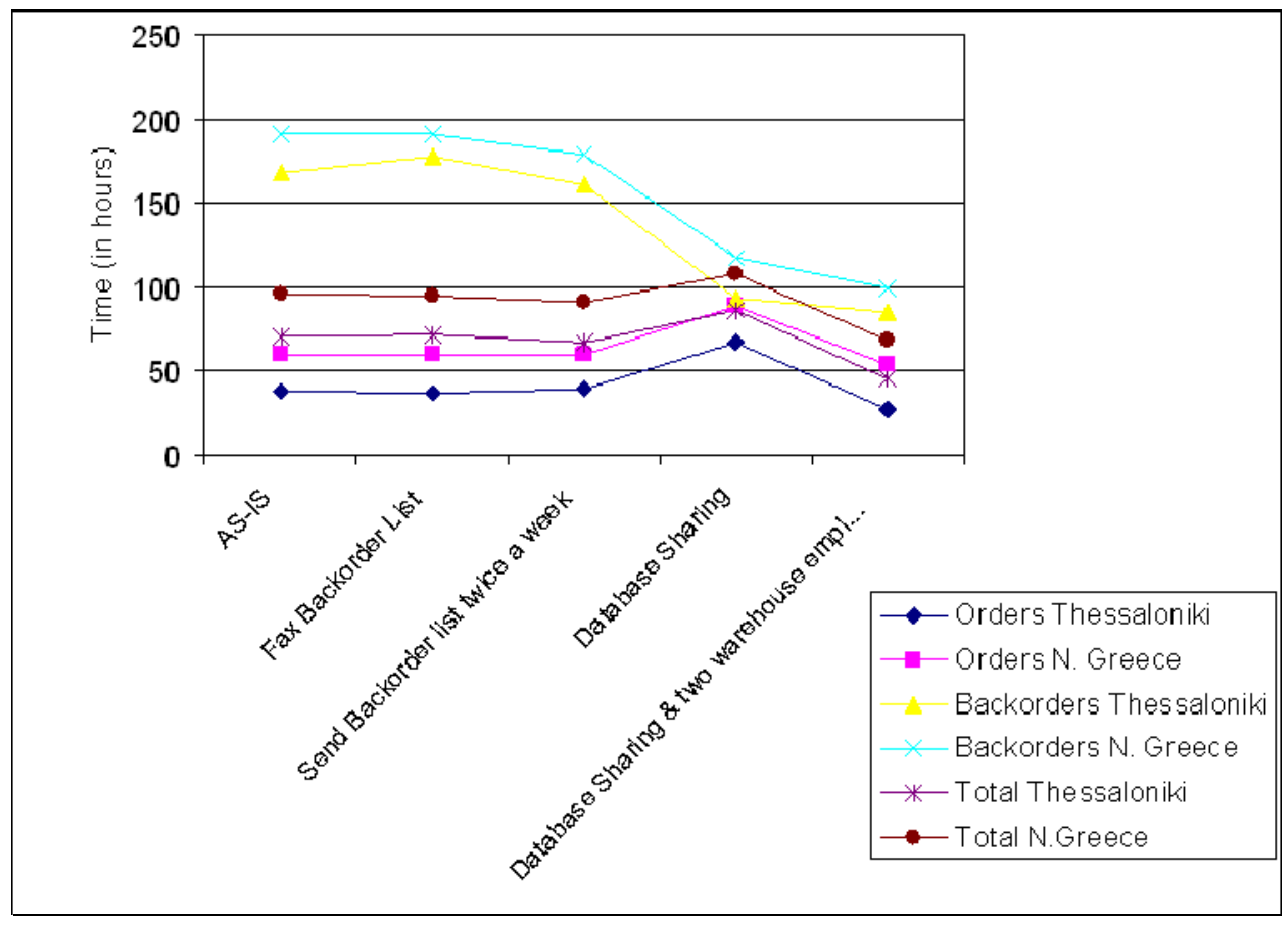

Figure 2 ASSESS-IT BPS Results

A deeper analysis of this situation suggests that the problem was due to the fact the ASSESS-IT approach concentrated on depicting the way IT affects processing time, but not in the way IT affects process performance. Business process modelling experiments showed that time was not a parameter that could affect process performance (Eatock et al., 2002). The experiments showed, however, that there are other IS parameters that affect BP performance. For example, the IS proposed in the case study was designed, amongst other things, to reduce the number of backorders. This information, though, could not be reflected in the business process model because the BP model is not designed to model the interactions between the 
processes and the information system. To do so, the BPS model should integrate the functionality of the proposed database system so the effects of using this system could be reflected in the processing time in the BPS model. Since this number could not be obtained, a variety of experiments were made using different figures based on experience. When reducing the percentage of backorders from $30 \%$ to $5 \%$ the results showed that overall processing time was reduced.

Two main lessons can be learned from the ASSESS-IT approach exercise.

1. The computer network infrastructure does not affect the performance of information systems used to support organisational processes. Consequently, the overall business process performance is not affected, in a significant manner, by changes to the $\mathrm{CN}$ infrastructure. Therefore, the use of a computer network model may be, in the context of this research, unnecessary.

2. The experimentation with different BP scenarios provided evidence that suggests that in order to portray the benefits that the use of an IS may bring to the business processes, it is necessary to obtain measurements of the way the IS affects BP performance. To do so, it was necessary to simulate the main functionality of the proposed system within the business process simulation model.

These lessons suggest that in order to provide a modelling approach that depicts the integration between BP and IT, it may be preferable to focus on the relationship between BP and IS alone. Furthermore, the insights gained from the experiments with different BP scenarios imply that the parameters that govern the relationship between business processes and information technology are not those that are related to time constraints but are instead those that are related to the way the IS functions. It was observed that time reduction of certain activities of the ordering process did not improve business process performance. On the other hand, IS performance measurements, such as the reduction of the number of 
backorders produced by the use of a database system, improved the overall process performance. These facts lead us to propose an alternative approach. The new approach should focus on the relationship between BP and IS, and more importantly, should model the core functionality of the proposed system.

\section{The ISBPS framework: Building Phase}

The new framework, namely ISBPS (Information Systems and Business Process Simulation), attempts to portray the integration of IS and BP using discrete-event simulation techniques. The major objective of the ISBPS is to provide guidelines to develop a simulation model that provides stochastic measurements of the way business process and information system behave, thus assessing the impact of the integration of a system in the business process as it evolves over time.

Although we can build on the knowledge and experience that exists with modelling BP, it is not clear yet how to model IS performance measurements. IS performance measurements are also known as information system’s Non-Functional Requirements (NFR) (Bennett et al., 1999, Sommerville, 1997). Most IS modelling techniques, however, aim to depict functional requirements. Non-Functional Requirements are not easy to represent in a measurable way, thus, a limited number of techniques and approaches can be found (Nuseibeh and Easterbrook, 2000). The ISBPS Framework can be used to identify NFR that affect IS performance and to model the behaviour of the IS and the BP as they evolve over time. To achieve this objective, the ISBPS framework is divided into sixteen tiers (see Figure 3).

The first tier can be considered as a simulation study on its own where the major aim is to develop a model of the way current business processes operate (as-is BP model). The results from ASSESS-IT showed that the development of as-is BPS models could help to identify possible process limitations and areas of improvement, including possible IS solutions. The BPS model derived from this tier will be used in subsequent tiers to a) identify process 
limitations, b) propose alternative BP and IS solutions, c) identify non-functional requirements, and d) experiment with the ISBPS model. Tiers Two to Eight are the guidelines to develop an as-is ISBPS model. The ISBPS model considers the way the impact that the functionality of the information system may have on business processes performance. Because this is an as-is model, the functionality of the current system should be portrayed. Tiers Nine to Twelve are the guidelines to develop the to-be ISBPS model considering the functionality of the proposed IS solution together with the corresponding changes to the BP. Tiers Thirteen to Sixteen use Banks et al (Banks et al., 2000) simulation steps (steps nine to twelve) to conclude the simulation study.
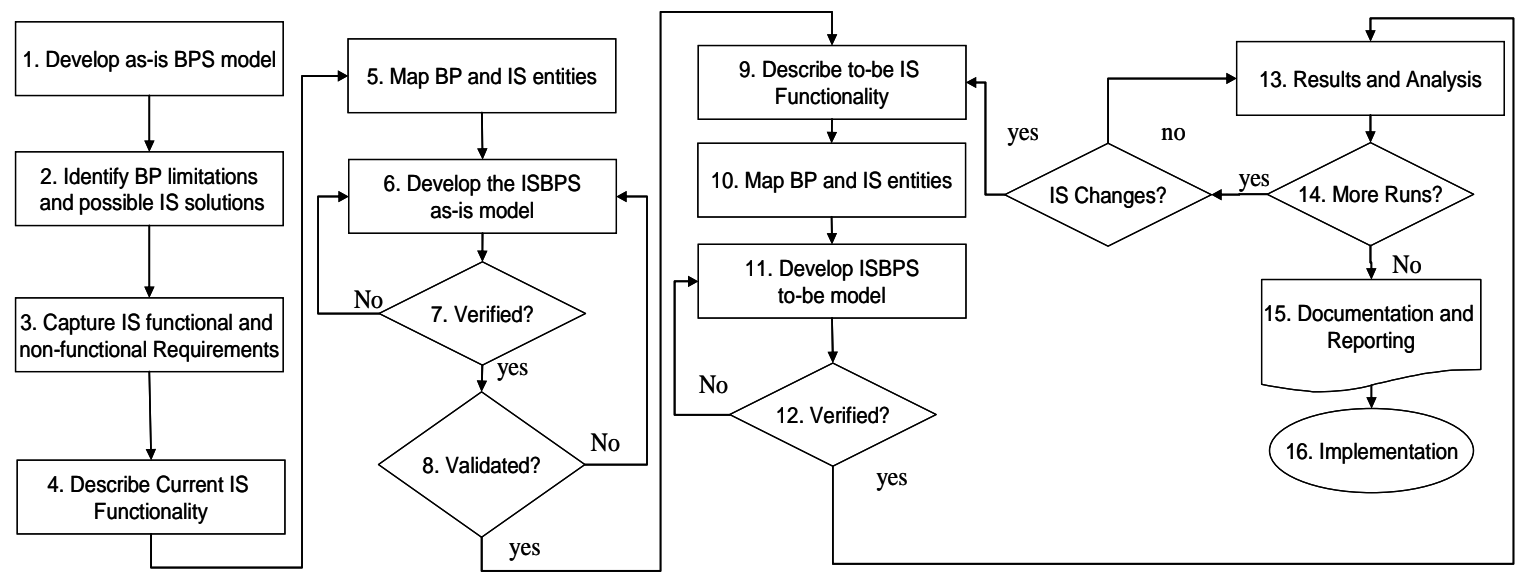

Figure 3 ISBPS Framework

The major aim of the ISBPS framework is to predict the benefits that the insertion of new IS design may bring to the business processes. , the following subsections are a detailed description of how tiers Two to Eight of the ISBPS framework achieve this aim. Since the other tiers are duplicates of these tiers, or directly taken from a more general and well-known simulation approaches (Banks et al. 2000), we only focus on tiers two to eight. A full description of the ISBPS framework tiers can be found in (Serrano, 2002). 


\subsection{Tier Two: Identifying BP limitations and possible IS solutions}

The as-is BPS model developed in Tier One will be used in this tier to identify current process limitations and to identify those processes where performance can be improved by the insertion of IS. To identify process limitations the performance measurements obtained from the BPS model should be assessed against organisational performance goals. The modeller can identify those processes where performance measurements are not satisfactory. Experimentation, with different scenarios can be used to identify possible causes that produce low process performance, such as poor process design, inappropriate use of resources, and so on. organisation

Once the proposed scenarios are tested, and process-related problems are identified, the insertion of IS should be considered next: what is the proposed IS system expected to do. IS and BP analysts should coordinate efforts to infer which processes can be benefited from the insertion of the IS and the ways it may improve process performance. In cases where the organisation is already supported by an IS, this step will identify those processes where IS are currently used.

\subsection{Tier Three: Identify and capture IS non-functional requirements}

This tier aims to identify and capture the expected performance of the information system. The ISBPS framework will use the BPS model developed in Tier One to identify performance requirements. To achieve this aim, BP and IS modellers should analyse those processes and activities that were considered to be affected by the proposed IS, previously identified in Tier Two. A closer analysis of the behaviour of such processes and activities can provide useful information to identify IS performance requirements The IS functionality models developed in Tier Two should be complemented with the findings of this tier. 


\subsection{Tier Four: Describe current IS functionality}

This tier aims to capture three major aspects of the current IS. One, to identify the overall workflow of the IS activities that are related to BP so this can be simulated in the as-is ISBPS model. Two, to identify the IS operations performed during the process flow, so they can be represented in the ISBPS model, and Three, to identify and understand how the data manipulated by the IS may affect BP entities, thus BP performance. This tier advocates the use of three UML modelling techniques: Activity models to capture the system's flow and identify relationships between activities. Collaboration diagrams to identify the collaboration between IS components and the IS operations performed. Finally, class models will be used to identify those classes that are related to the business entities. Although the ISBPS framework advocates the use of UML, other IS modelling techniques that provide same information can also be used.

\subsection{Tier Five: Map BP and IS entities}

The ISBPS framework defines two different types of entities. Business Entities (BE) which are those entities found at the business level. BE usually represent real-life objects such as machines and employees, and are used in the BP model to represent process behaviour. The second entity type defined in the ISBPS framework is called a Information System Entity (ISE). ISE are the collection of entities that represent the information contained in a BE.

This tier will use the IS models created in Tier Four to create a table, namely IS Entity/Business Entity Relationship (ISEBER), which relates the entities that are used in the BP model, their corresponding information system entities, the activities where ISE are used to control IS flow, and the operations performed when using these ISE. The first step to build the ISEBER table is to identify all BE used at the business process level and their corresponding ISE. In the second step, the activity diagrams developed in Tier Four will be 
used to identify which processes and/or activities use the ISE identified before. The activities/processes are registered in the process/activity column. Finally, collaboration

\begin{tabular}{|l|l|l|l|}
\hline $\begin{array}{c}\text { Business } \\
\text { Entity }\end{array}$ & $\begin{array}{l}\text { Information System } \\
\text { Entity }\end{array}$ & Process/Activity & \multicolumn{1}{|c|}{ Operations } \\
\hline Order & order_id & create an order & To keep track of the order \\
\hline & product_id & $\begin{array}{l}\text { check warehouse } \\
\text { and reduce } \\
\text { inventory levels }\end{array}$ & $\begin{array}{l}\text { To identify the product } \\
\text { requested }\end{array}$ \\
\hline Backorder & product_quantity & $\begin{array}{l}\text { check warehouse } \\
\text { and reduce } \\
\text { inventory levels }\end{array}$ & $\begin{array}{l}\text { To check product_stock stock } \\
\text { levels against product_stock }\end{array}$ \\
\hline
\end{tabular}

Table 1 ISEBER Table example

diagrams will be used to identify the IS operations that use or transform a given ISE or BE in each of the activities. In doing so, each row of the ISEBER table provides information about a given IS entity, to which business entity it is linked, in which activities it is involved, and which is the aim pursued by the IS when using this specific ISE (IS operation). An example of a ISEBER table is shown in Table 1.

\subsection{Tier Six: Develop the as-is ISBPS model}

This tier aims to develop the as-is ISBPS model using the information collected in previous tiers, in particular, the information captured in the ISEBER table. To develop the asis ISBPS model the modeller needs to identify all BE and ISE that are related to business performance and the business rules, including informational aspects, that may affect them.

The ISBPS framework considers the IS as a black box (Figure 4).

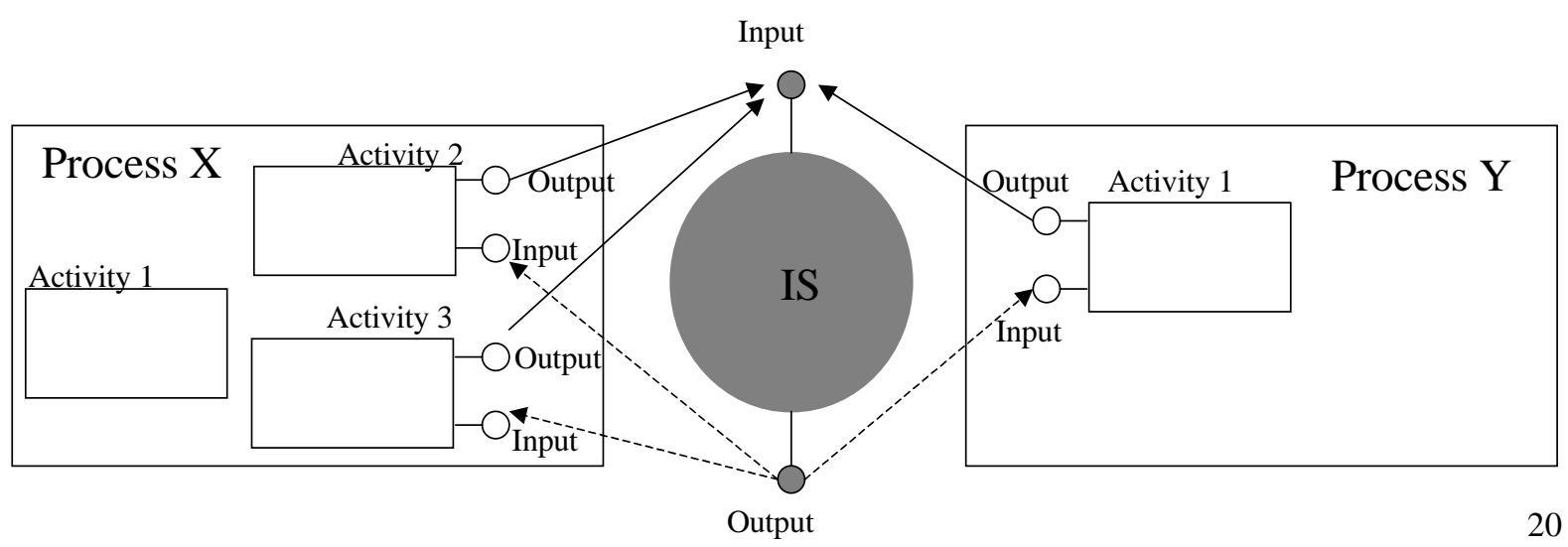


The relationship between BP and IS can be seen as relationships between input and output interfaces in each process and/or activity with the corresponding interfaces in the IS. For instance, the relationship between BP output-IS input interfaces is used to obtain information contained in BP entities (BEs) to perform the corresponding operations in the IS. Subsequently, the relationship between IS output-BP input interfaces is used to reflect the changes that the IS produces on the BP entities. It can be observed in Figure 4 that any input to the IS is reflected at any activity across all processes.

To develop the as-is ISBPS model, this tier will modify the as-is BPS model developed in Tier One so it includes the information system behaviour. In doing so, it is assured that the components used in the as-is BPS model, such as data distributions, resources, and entities are consistent in both models. The development of the as-is ISBPS model is divided in the following steps:

One. Represent the links between information system entities (ISE) and business entities (BE). ISE should be represented in the ISBPS model as attributes of BE. This information can be obtained from the ISEBER table.

Two. Program the functionality of the system. The modeller needs to insert programming code that represent the business conditions that produce changes to ISE and BE together with the consequences of these changes. Most of current process simulation software provides the facilities to add programming code to any activity and make changes to different model elements, including entities and attributes. Furthermore, the modeller can chose the simulation conditions when the code should be processed. For example, the code can be processed when an activity accepts an entity or when the latter is released from the activity. This adds the flexibility of choice to select the most suitable condition to run the code. To achieve this aim the modeller can use the information provided by the ISEBER tables. ISEBER tables indicate in which processes/activities the code should be inserted. In case that 
the information described in the ISEBER tables cannot provide enough details about the functionality of the system in a given activity, this information can be obtained analysing the activity and collaboration diagrams developed in Tier Four.

\subsection{Tier Seven: Verify the as-is ISBPS model}

This tier aims to ensure that the computerised representation of the model is correct. The ISBPS model is, per se, a simulation model. Thus, existing techniques to verify simulation models apply to the ISBPS model. Detailed information about verification techniques can be found in Banks et al. (Banks et al., 2000) and Law and Kelton (Law and Kelton, 2000).

\subsection{Tier Eight: validate the as-is ISBPS model}

This tier aims to ensure that the model is an accurate representation of the real system. Because the as-is ISBPS model is based on the as-is BPS model developed in Tier One, and the latter has already been validated, this tier aims to validate the as-is ISBPS model against the as-is BPS model. To validate the as-is ISBPS model, performance measurements from the as-is ISBPS model are compared against those from the as-is BPS model. Amendments to the ISBPS model should be done until the results of the as-is ISBPS model match, in the best possible way, the results from the as-is BPS model.

\section{The ISBPS Framework Testing and Validation: Discovery Phase}

To evaluate the ISBPS framework, the same case study was used as for the ASSESS-IT framework. To this end, it was agreed that the proposed IS should accomplish the aims described in the following list.

- The IS should automatically update inventory levels so a real-time inventory level could be monitored by both organisations.

- The IS should automatically produce a backorder whenever a given product is out of stock. 
- When a backorder is produced or the inventory level of a given product is below the figures established by the organisations, the IS should request the replenishment of this product.

- When a replenishment cargo is delivered, the inventory levels should be updated and reflected in real-time.

Two IS non-functional requirements related with performance measurements were identified for the proposed IS. The first and most important requirement was requested by Org-A and establishes that the overall delivery time, including backorders, should be 24 hours for products delivered within the city of Thessaloniki, or within 48 hours for the rest of northern Greece. This means that it is expected that the introduction of the new IS would reduce current delivery times so they fit the requirements previously mentioned. The second requirement was obtained during experimentation of the BPS model. It was detected that the backordering process was a major system bottleneck, and that delivery times depended on this process. It was demonstrated that when reducing the number of backorders, the overall processing time was significantly reduced. Therefore, a performance requirement that was not identified before is related to the percentage of backorders produced by the IS.

The results of the ISBPS model reported a significant reduction in the totality of lead times, in particular, backorder lead times. Figure 5 shows that backorder lead-time for both, Thessaloniki and Northern Greece were reduced in more than 80\% (ISBPS column).

Figure 6 shows the number of orders and backorders produced by the different models. An interesting observation in Figure 6 is that the percentage of backorders produced by the ISBPS model reported an increase of nearly 10\% (ISBPS column) in relation to the figures reported for the BPS as-is model (as-is column), a situation that contradicts the assumption made that the new IS would reduce the number of backorders. A possible reason that causes this situation is that the minimum product stock level used in the model (10 products) 
produces a greater number of backorders. This event, though, does not affect backorder leadtime because the new system schedules delivery times in a more accurate manner than the manual system.

Experimenting with the ISBPS model showed that a possible way of reducing backorders and consequently lead time is to increment the minimum stock level for each product. The results suggested a minimum stock level of 100 items for each product helped to reduce:

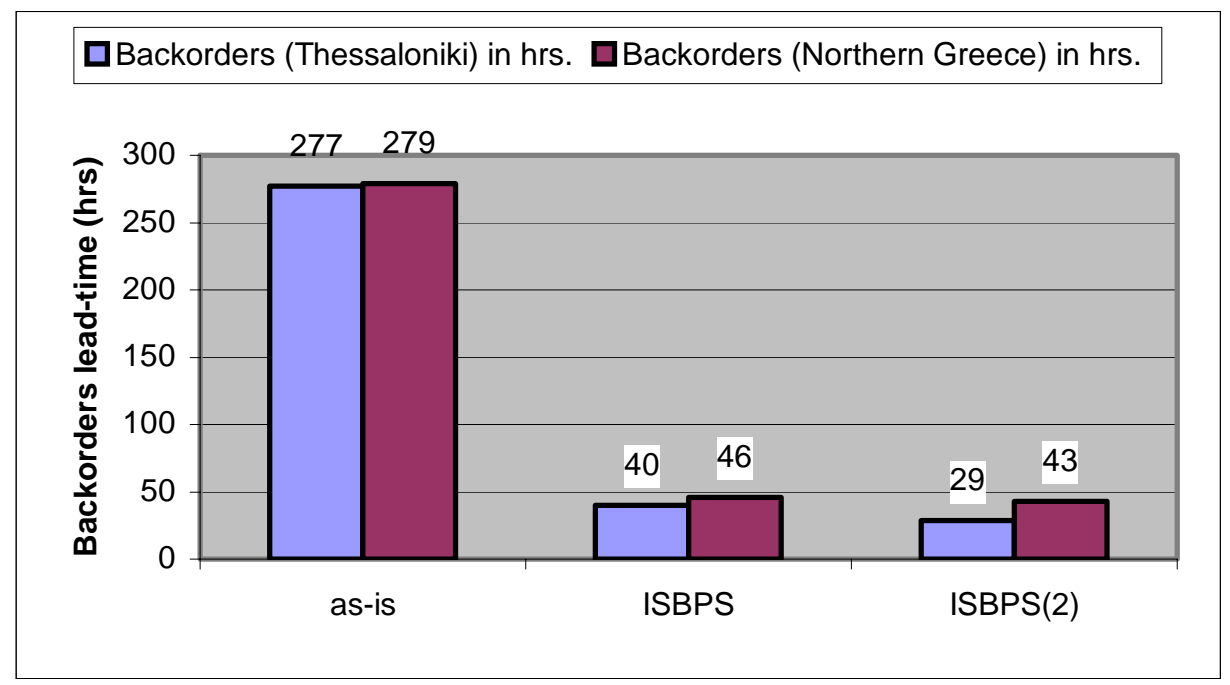

Figure 5 ISBPS Simulation Results (Backorder Lead-time)

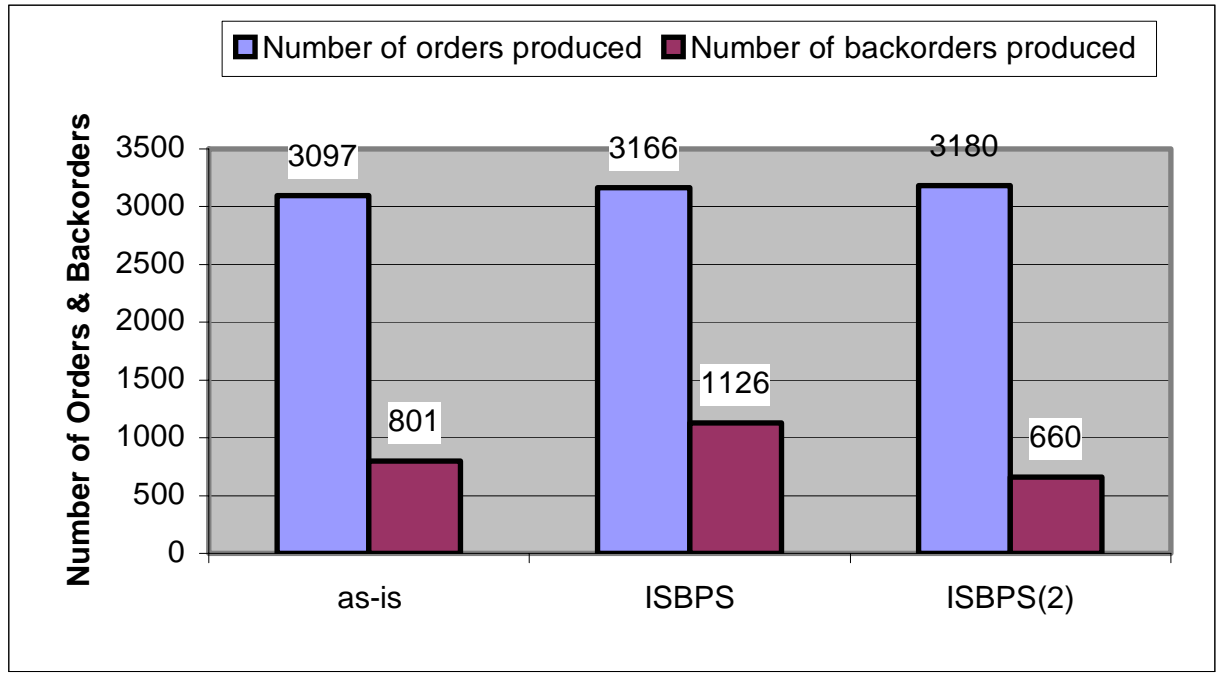

Figure 6 ISBPS Simulation Results (Number of Order and Backorders)

1. Ordering and backordering lead-time (see Figure 5 ISBPS(2) Column) and

2. The number of backorders (see Figure 6 ISBPS(2) column). 
These experiments show that the ISBPS framework is able to represent the relationship between the business processes and information technology in a better way than the ASSESS-IT framework. Changes in the IT would not reflect any changes in the BP with the ASSESS-IT framework. Changes in the IS, by focusing on representing the functionality of the proposed IS, however, do present changes in the BP as made visible with the ISBPS framework.

\section{Discussion of the ISBPS Framework}

This paper starts by supporting the argument that discrete event simulation can be a useful technique/tool that can aid to model the integration of business process and information technology. The literature provided evidence that suggested that the creation of dynamic models, such as simulation, offer opportunities for evaluating BP and IS (Paul et al., 1998), because the provide quantitative information about the model in question (Pegden et al., 1995). This was corroborated when analysing the results provided by the simulation models derived from the ISBPS framework. Such results rendered quantifiable data that reflected the effects that the integration of a database system with the business processes may produce on the processes themselves (see figures 5 and 6). Furthermore, the analysis of the literature also suggested that the integration of information systems into business process should not be assessed by looking at the automation of processes, but rather as the effects that changes on any of them may produce in the system as a whole (Hammer, 1990, Grover et al., 1994). The results derived by the application of the ASSESS-IT framework provided evidence that supports this argument.

The ASSESS-IT modelling framework looked to obtain quantifiable measurements of the way changes to the ICT infrastructure, namely information systems and computer networks, may affect business performance. When developing the CNS models, however, it was observed that the only way the CN infrastructure could affect BP performance was related to 
time delays. The measurements obtained by the CNS model were used on those processes that changes to the $\mathrm{CN}$ infrastructure affect process performance. It was observed that the fact of using a database system to speed up the order and backordering processes did not improve the performance of the business process as a whole. By looking at Figure 2 it was seen that those scenarios that used a database system did not improve the total ordering lead time. This was due to the fact that the ASSESS-IT models evaluate IT solutions based on IS/CN time performance. A deeper analysis of the models suggested that in order to measure the integration of the database system into the business processes it was necessary to depict the way the database system handles the backorder process. This could only by achieved if the basic functionality of the proposed database system was modelled within the business processes. These results were used to derive an alternative framework that concentrates on integrating the functionality of the proposed IS into the business process simulation model: The ISBPS Framework. From the lessons learned from the ASSESS-IT framework, the ISBPS framework provides guidelines to create simulation models to model the integration of information systems with the business processes. By doing so, the models will provide quantifiable information of the effects that the integration of an information system may have on the processes as a whole, as suggested by the literature review (Hammer, 1990, Grover et al., 1994). Conclusions, advantages and limitations of the ISBPS framework are discussed next.

\section{Conclusions}

This paper argues that despite the fact there is a need to model the integration of BP and IT, existing BP and IS design approaches are not capable of modelling this interaction. Based on the literature review and the results derived from a research project, namely ASSESS-IT, this paper argues that simulation is a suitable candidate to model the interactions between BP 
and IS. Consequently this paper discussed the rationale behind the ASSESS-IT framework and analysed the results provided by its application in a case study.

The results derived from the ASSESS-IT framework suggest that the relationship between BP and IT can be better described as the relationship between business processes and the information system that support those processes, and not as a ( as it was initially thought in the literature review and by the ASSESS-IT framework. Furthermore, the results from the models derived from the ASSESS-IT framework suggested that in order to depict the interactions between BP and IT it is necessary to portray the core functionality of the IS that supports the business process. This paper used this knowledge to propose a new simulation framework, namely ISBPS, to develop simulation models that depict business process and information systems performance.

The simulation results provided by the ISBPS model suggests that it is possible to obtain performance measurements of the integration of a given system in the business process by looking at the data derived by the simulation model. For example, the ISBPS model provided quantifiable metrics of the IS, such as the number of backorders that the IS produces over a given period of time given a particular business process scenario. These measurements helped to investigate the way IS may affect process performance.

Another outcome of the ISBPS framework is that it rendered evidence that suggests that simulation techniques can be used as an aid to design simulation models that depict the integration of business processes and information systems. For instance, the analysis of the traditional BPS model proposed in Tier Two of the ISBPS framework provided more information to identify those areas where BP could be improved by the insertion of an IS. This information cannot be obtained by the use of traditional IS modelling techniques since they cannot always predict the way the IS will behave in practice. For example, based on the IS description provided by static models, it was thought that the IS would significantly reduce 
the number of backorders. After running the ISBPS simulation model, it was shown that this was not the case.

The experiment showed that depicting the behaviour of the IS and the effects that the latter would have on the processes is feasible, however, this was not an easy task. Despite the simplicity of the case study used to test the ASSESS-IT and ISBPS frameworks, the development of the model proved to be complex. It is thought that the higher the complexity of the IS the harder the construction of the simulation model. Hence, further research can be focused on testing the ISBPS framework with more complex IS. Regardless of these drawbacks, the results of the experiment suggested that the new IS would improve the performance of the processes. Furthermore, it was noticed that the performance of the process did not depend only on the functionality of the information system but also on accurate changes to the business process themselves. This shows that business processes and the information systems are closely integrated and further research in this direction may help to understand this relationship in more detail. Finally, one of the major reasons of the complexity of this new approach was due to the fact that the discrete-event simulation tool used in our example, namely Simprocess (C), was designed to model and simulate business process and offered limited capabilities to model and simulate the functionality of the information system. Further research in this area will also help to identify/design simulation mechanism that offer better capabilities to model the elements required to simulate the integration of business process with information systems.

\section{References}

Agerfalk, P. J. and Eriksson, O. (2004) Action-oriented conceptual modelling. European Journal of Information Systems, 13 (1),pp.80-92.

Banks, J., Carson, J. S., Nelson, B. L. and Nicol, D. M. (2000) Discrete-event System Simulation, Prentice-Hall, Upper Saddle River, NJ.

Benbasat, I., Goldstein, D. K. and Mead, M. (1988) Letter to the Editor. MIS Quarterly, 12,pp.522. 
Bennett, S., McRobb, S. and Farmer, R. (1999) Object-oriented Systems Analysis and Design Using UML, McGraw-Hill, London.

Braa, K. and Vidgen, R. (1995) Action Case: Exploring The Middle Kingdom in IS Research Methods. Bodker (Eds) Proceedings of Third Decennial Conference Computers in Context: Joining Forces in Design, Aarhus, Denmark, August 14-18. pp. 50-60.

Childe, S. J., Bennett, J. and Maul, J. (1994) Frameworks for Understanding Business Process Re-engineering. International Journal of Operations \& Production Management, 14 (12),pp.22-34.

Davenport, T. H. (1993) Process Innovation: Reengineering Work through Information Technology, Harvard Business School Press, Boston, MA.

Davenport, T. H. and Short, J. E. (1990) The New Industrial Engineering: Information Technology and Business Process Redesign. Sloan Management Review, 31 (4),pp.11-27.

Eatock, J., Paul, R. J. and Serrano, A. (2002) Developing a Theory to Explain the Insights Gained Concerning Information Systems and Business Processes Behaviour: The ASSESS-IT Project. Information Systems Frontiers, 4 (3),pp.303-316.

Giaglis, G. M. (1999) Dynamic Process Modelling for Business Engineering and Information Systems, PhD Thesis, Brunel University, London.

Giaglis, G. M., Paul, R. J. and O'keefe, R. M. (1999) Integrating Business amd Netrwork Simulation Models for IT investmenty Evaluation. Logistics Information Management, 12 (1/2),pp.108-117.

Gladwin, B. and Tumay, K. (1994) Modelling Business Processes with Simulation Tools. Tew, J. D., Manivannan, S., Sadowski, D. A. and Seila, A. F. (Eds) Proceedings of the 1994 Winter Simulation Conference, Lake Buena Vista, FL, December 11-14. pp. 114-121.

Grover, V., Fielder, K. D. and Teng, J. T. C. (1994) Exploring the Success of Information Technology Enabled Business Process Reengineering. IEEE Transactions on Engineering Management, 41 (3),pp.276-284.

Hammer, M. (1990) Reengineering Work: Don't Automate, Obliterate. Harvard Business Review, 68 (4),pp.104-112.

Hammer, M. and Champy, J. (1993) Reengineering the Corporation: A Manifesto for Business Revolution, Harper Collins Publishers, New York, NY.

Hedman, J. and Kelling, T. (2003) The business model concept: theoretical underpinnings and empirical illustrations. European Journal of Information Systems, 12 (1),pp.4959.

Hlupic, V. and Robinson, S. (1998) Business Process Modelling and Analysis Using Discrete-Event Simulation. Medeiros, D. J., Watson, E. F., Carson, J. S. and Manivannan, M. S. (Eds) Proceedings of the 1998 Winter Simulation Conference, Washington, DC, December 13-16. pp. 1363-1369.

Irani, Z., Ezingeard, J. N., Grieve, R. J. and Race, P. (1999) A Case Study Strategy as Part of an Information Systems Research Methodology: A Critique. International Journal of Computer Applications in Technology, 12 (2/3/4/5),pp.190-198.

Kettinger, W. J., Teng, J. T. C. and Guha, S. (1997) Business Process Change: A Study of Methodologies, Techniques, and Tools. MIS Quarterly, 21 (1),pp.55-80.

Law, A. M. and Kelton, D. W. (2000) Simulation Modelling and Analysis, McGraw-Hill, New York, NY.

Law, A. M. and McComas, M. G. (1994) Simulation of Communication Networks: The State of the Art. IEEE Communications, 32,pp.44-50.

Lee, A. S. (1989) A Scientific Methodology for MIS Case Studies. MIS Quarterly, 13 (1),pp.32-50. 
Levas, A., Boyd, S., Jain, P. and W.A. Tulskie (1995) The role of modelling and simulation in business process reengineering. Alexopoulos, A., Kang, K., Lilegdon, W. R. and Goldsman, D. (Eds) Proceedings of the Winter Simulation Conference, pp. 13411346.

MacArthur, P. J., Crosslin, R. L. and Warren, J. R. (1994) A Strategy for Evaluating Alternative Information System Designs for Business Process Reengineering. International Journal of Information Management, 14 (4),pp.237-251.

Nuseibeh, B. and Easterbrook, S. (2000) Requirements Engineering. (Eds) Proceedings of the 22th International Conference on Software Engineering, Limerick, Ireland, June 4-11. pp. 35-46.

Painter, M. K., Fernades, R., Padmanaban, N. and Mayer, R. J. (1996) A Methodology for Integrating Business Process and Information Infrastructure Models. Charnes, J. M., Morrice, D. J., Brunner, D. T. and Swain, J. J. (Eds) Proceedings of the 1996 Winter Simulation Conference, Coronado, California, December 8-11. pp. 1305-1312.

Paul, R. J., Hlupic, V. and Giaglis, G. (1998) Simulation Modeling of Business Processes. D., A. and Edgar-Neville (Eds) Proceedings of the 3rd U.K. Academy of Information Systems Conference, Lincoln, U.K.

Pegden, C. D., Shannon, R. E. and Sadowski, R. P. (1995) Introduction to Simulation Using SIMAN, London:McGraw-Hill.

Serrano, A. (2002) Stochastic Information Technology Modelling for Business Processes, Unpublished $\mathrm{PhD}$ Thesis, Brunel University, London.

Sierhuis, M., W.J. Clacey, Seah, C., Trimble, J. P. and Sims, M. H. (2003) Modeling and simulation for mission operations work system design. Journal of Management Information Systems, 19 (4),pp.85-128.

Sommerville, I. (1997) Software Engineering, Addison-Wesley, Wokingham.

Themistocleous, M. (2004) Justifying the Decisions for EAI Implementations: A Validated Proposition of Influential Factors. Journal of Enterprise Information Management, 17 (2),pp.85-104.

Themistocleous, M. and Irani, Z. (2001) Benchmarking the Benefits and Barriers of Apllication Integration. Benchmarking: An International Journal, 8 (4),pp.317-331.

Vreede, G. J. (1998) Collaborative Business Engineering with Animated Electronic Meetings. Journal of Management Information Systems, 14 (3),pp.141-164.

Vreede, G. J. and Verbraeck, A. (1996) Animating Organisational Processes: Insight Eases Change. Journal of Simulation Practice and Theory, 4 (3),pp.245-263.

Warren, J. R., Crosslin, R. L. and MacArthur, P. J. (1995) Simulation Modeling for BPR: Steps to Effective Decision Support. Information Systems Management, 12 (4),pp.3242.

Weick, K. E. (1984) In The Information Systems Research Challenge(Ed, McFarlan, F. W.) Harvard Business School, Boston, Mass., pp. 111-129.

Yin, R. K. (1994) Case Study Research : Design and Methods, Sage, Thousand Oaks, California. 